\title{
“Center or periphery?": regional music in contemporary China
}

\author{
Frederick Lau
}

Received: 2 February 2015/Revised: 17 February 2015/Accepted: 17 February 2015 /

Published online: 13 March 2015

(C) Academy for International Communication of Chinese Culture 2015

\begin{abstract}
Chinese regional cultures have often been viewed as subsidiary to a perceived unified national culture. Implicit in this perspective is the validation of the prestige, power, and authority of the center. This view invariably renders regional cultures insignificance and trivial. A closer look at regional cultures in situ reveals a reality contrary to perceptions held by outsiders. For the locals, regional culture shapes their sense of self and cultural ethos. Using examples of contemporary regional music as lenses, this paper explores what regional music is, what it means to the locals, and its relationship to national music and culture. I suggest that as a domain of culture, music often functions as an emblem for marking identities because of the sentiment and sensibility it evokes. In the post-1949 era, Chinese scholars and musicians often view regional music, "difang yinyue" disparagingly as they attempt to establish a pan-Chinese musical style known as minzu yinyue or minyue. Although acknowledging unique features of various "difang yinyue," regional music has been treated as an object of exoticism and as flavors used only to enrich their original compositions. The prevailing notion is that regional music-a distant voice from the margin and a sign of backwardness inherited from the pastneeds to be developed and brought into the present. Despite this seemingly patronizing attitude and constant criticism, the practice of regional music receives continuous support from the local population and it has witnessed an increase in popularity in recent years. In particular, this paper addresses the question of local identity as manifested in two regional musical traditions, namely Jiangnan Sizhu in Shanghai and Xianshi in the Guangdong Chaozhou area and in Bangkok. The performance of music and musical discourse undoubtedly evolves around the question of identity. Through a discussion of the music and performance practice in these two areas, I argue that the maintenance and continuity of any regional music
\end{abstract}

F. Lau (ه)

Music Dept, University of Hawai` i at Mānoa, 2411 Dole Street, Honolulu, HI 96822, USA

e-mail: fredlau@hawaii.edu 
enables its practitioners to draw a boundary between themselves and others and also provide them with a voice in the state controlled cultural space.

Keywords Chineseness - Chinese culture - Cultural identity ·

Chinese regional music $\cdot$ Regional identity $\cdot$ Center and periphery ·

Music and place $\cdot$ Diaspora

\section{Introduction}

Anyone who is familiar with Chinese culture knows that local or regional cultures exist, no matter how subtle the differences. ${ }^{1}$ Regional characteristics can be found in language, custom, religion, cuisine, music, performing arts, and expressive culture. For a long time, these unique local features have been subsumed under a general, amorphous, and all-encompassing rubric called Chinese culture. While this term has been frequently invoked to refer to all things Chinese, more and more scholars are beginning to question its effectiveness in communicating what it really means and what it implies when the notion of China, the Chinese nation, and Chinese has changed drastically in recent decades. Regional cultures have been under-valued in the study of Chinese culture and it is only in the late 20th century that regional cultures have been recognized by scholars as significant and necessary ingredients in the making of national identity (Honig 1992; Rowe 1989; Siu 2010; Ho 2005; Lee 1999). Conceptualizing national culture as something located in the center and regional culture in the periphery inadvertently implies China is a hierarchical and polarized organization in which the center shapes the periphery and the flow of political, economic and cultural energy inevitably emanated from top down and inside out. Clearly this is not the case and the relationship between the two sides is more fluid and dynamic than suggested. In fact, some regional cultures have been co-opted to become icons of national culture and were seen to have the power to transcend regional boundaries to stand in for the nation. The recognition of regional cultural practice such as Peking Opera, Kunqu opera, maotai liquor from Guizhou, mala hotpot from Sichuan, Shanghai culture, and Hakka culture are excellent examples of regional culture receiving national and global attention. Increased flows of people and ideas in the modern age have contributed to this shift, as have the emergence of regional-now-turned global centers such as Beijing, Shanghai, Guangzhou, Xiamen, Wuhan, Chengdu which began to exert greater influence on China's political and economic arenas in the 19th and 20th century. Thus, what might once have been thought of as a viable model of delineating Chinese culture in terms of the center and periphery binary can no longer adequately explain the symbiotic relationship and dynamic interaction between what was once considered China's cultural fringe and the center.

\footnotetext{
1 An abridged version of this paper was presented at the "International Communication of Chinese Culture," an international conference held at the Beijing Normal University November 28-29, 2014. Many people have commented on my paper and I particularly would like to thank Austin Luo Jun, Adrien von Fercht, Gary Sigley for their insights, friendship, encouragement, and humor.
} 
The increasing prominence of regional cultures not only challenges conventional ways of mapping and defining Chinese culture, it also draws our attention to the fact that regional cultures are "things" that are produced locally, marked culturally and signified according to its unique social context (Kopytoff 1986, p. 64). By focusing on the nature of "social" things, we can thereby avoid the trap of relying on overdetermined social and historical factors and matrix in explaining Chinese culture and society. Using two regional instrumental music genres as the focus of my paper, I examine the identity and meaning of Chaozhou xianshi (string) music and jiangnan sizhu (silk and bamboo) music in Shanghai and what these musics mean to their practitioners in different situations in order to reveal the problems of defining regional music using binaries such as center/periphery and core/margin. In the process, I also point out the ambiguity of labels such as regional music or Chinese music in national and transnational contexts as a way to help us think about productive alternatives of talking about China culture at large (Robbins 1989).

The particularity and ethos of regional music deconstructs a preconceived and essentialized notion of Chineseness. In a provocative article on Chineseness, Rey Chow observes that this ethnic label remains highly problematic in its application. While the label Chinese is continually used by the West to stigmatize and ghettoize Chinese culture, Chow also notes that Chinese scholars' obsession with this label inevitably draws an unnecessary imaginary boundary between China the West. The victim mentality or "logic of the wound" that underlies the latter's view is basically a kind of cultural essentialism that runs parallel to the Western orientalist view of the East (Chow 1998, pp. 4-7). In her view, Chineseness as a label remains a reactive construction of ethnicity both for insiders and outsiders and requires a critical reassessment of ethnicity as a site of difference before we can fully erase it as an ethnic qualifier.

Regional music is also used by its practitioners to construct Chineseness according to their own cultural logic and conditioning. However, the question that interests me about regional instrumental music here is not to determine the nature of Chineseness in Chinese regional music, but to understand how it functions and makes sense for insiders, especially the people who perform and consume it. In other words, how does a regional music take on unique identities within and outside its origin contexts? What are some of the crucial factors that are at work? In order to examine the slippage of terms such as Chinese music and regional music, Appadurai's notion of social imagination (1996) is particularly useful as it refers to the powerful effect of collective imagination in cementing group solidarity via the media, printed culture, performing arts and expressive strategies. What does it mean when we talk about regional music-difang yinyue or minjian yinyue in an era when the term China and difang carries multiple meanings and implications? Is difang yinyue merely a mirror image of music in the "center" or something that produces it? Answers to these questions undoubtedly lead us back to issues related to identity, authority, and positionality.

A drastic departure from the essentialized view of identity of an earlier period, identity is now viewed as fluid and context-specific. It is constructed in response to particular historical and social circumstances according to the collective imagination of a group of people. As such, it is often a product of power relationships 
(Honig 1992; Mercer 1992; Turino 1991; Waterman 1990; Wong 1985; Frith 1996). Given the fluid nature of identity formation, at any given moment one identity can simultaneously carry multiple layers of meaning according to the interpretative and encoding scheme utilized by the individual or group. James Clifford reminds us that human identities are relational, conjunctural, and often hybridized (Clifford 1988, pp. 10-11). They are not fixed categories, but are always in the process of articulation and becoming. Furthermore, the need to define oneself or locate the "others" in different categories often arises when one's identity is challenged, questioned, or in crisis (Mercer 1992). This reactive marking of difference and exclusivity as a response inevitably calls into question issues of power and subjectivity that cut across all social and cultural domains and relationships. In this sense, dualistic distinctions such as national/local, us/them, center/periphery are no longer viable and sufficient categories, but rather manifestations of the dynamic processes of "defining" and being "defined" (Bourdieu 1977; Turino 1989).

Based on ethnographic data I collected in Chaozhou region (PRC), Bangkok (Thailand) and jiangnan sizhu music in Shanghai, I suggest that the identity of xianshi and jiangnan sihzu music, and regional music in general, rests primarily on the condition of a "community of sentiment" that allows a group of people to imagine and feel things together as they define their reality and social boundaries (Appadurai 1996, p. 8). Any music is capable of becoming the raw material in constructing landscapes of collective aspirations in regard to ethnicity and identity. For example, for state-employed professional zhuanye musicians, regional genres such as xianshi and jiangnan sizhu music are considered undeveloped, exotic, and backward. However, for local practitioners, the sonic specificities and aesthetics of the music is part of the symbolic repertoire that maintains and gives meaning to local consciousness and sense of belonging. But for the Thai-Chinese in Thailand, this music means totally different from the previous groups because in the Thai context, xianshi is an art form that defines them as Teochew (Chaozhou) Chinese. The analogy extends in similar directions for musicians and residents in Shanghai where jiangnan sizhu music represents the essence and ethos of the jiangnan [south of the Yangzi River] spirit and cultural style. For these reasons, I argue that there is no one single meaning of xianshi and jiangnan sizhu music or any type of difang yinyue for that matter, only multiple ways that the music has been incorporated and insinuated into the social through a process of imagination and resignification.

\section{Making China's national music}

The idea that China, as a modern nation, should have its own national music began in the early 20th century. Music scholars began to debate what it takes to create a national music for China (Lau 2008, pp. 30-34). Following this, the post-1949 Chinese government also began to implement the project of establishing a uniform approach to all forms of music making in order to define their identity. One of the most significant steps was to create a class of state-employed zhuanye professional musicians whose primary task was to formulate a nation-wide homogenous musical practice in order to underscore the communist socio-political orientation and 
identity of the new China. Armed with this mission, zhuanye professional musicians called for the establishment of a musical idiom that on the one hand "adhere[s] to the essence of traditional musical practice" and on the other "continuously being original and innovative" (Ding 1964). In practice, this slogan was translating into superimposing selected traditional music elements on the European tonic-dominant harmonic framework. As a state guideline, this new musical language was accepted as a normative practice among all music institutions, and new compositions replaced traditional ones as the new canon, thereby setting the standard and creative boundaries for government-approved music.

As state-employed musicians who were also part of the state political machinery, these new cultural elites began to differentiate themselves from those who maintained different musical preferences and aesthetics. Criticisms were launched at those who failed to embrace the new style, stigmatizing them as antirevolutionary (fangeming), backward (luohou), and unsophisticated (tu). This attitude further strengthened the legitimacy and prestige of new music practices over traditional ones.

In the process of creating a national music since 1949, the conception of Chinese music was also consolidated by centering this new style and peripherizing all regional music and its deviations. In the name of kexuehua [scientific] and fazhen [development], local and regional music was condemned as static, museumized traditions of the past that were incommensurate with the new image of Chinese music. Furthermore, the term difang yinyue, literally music of all regions, was relegated to traditional music of the Han people while the term shaoshu minzu minyue [literally music of the national minority] was introduced to refer to music of the national minorities, thereby artificially creating false distinctions between genres, categories, aesthetics, and people. By defining regional music as outside the limits of the new music style, the logic of musical nationalism construed local music as something incompatible with the superiority and political correctness of the new style.

Ignored in this formulation were the sensibilities and the unique musical characteristics associated with each local music tradition and music's inherent meaning in relationship to its practitioners. Zhuanye professional musicians merely regarded local practices as raw materials and exotic colors which could be used to enhance the flavor of new compositions. While they romanticized these "crude" and "unsophisticated" regional sounds as embodiments of the essence and true spirit of the people, they also believed that it was only through the process of refinement and development that the essence could be extracted and revealed. This view eventually gave rise to the standard practice of collecting regional music for the purpose of enriching their compositions. Many students at the conservatories are still required to conduct field research to collect raw materials for their compositions is a telling example of this mentality (Yang 1994, p. 307).

\section{Chaozhou Xianshi in China}

Chaozhou, now part of China's coastal special economic zone, is an area in the NE coast of Guangdong province. It has a unique language and culture that is different 
from their Cantonese counterparts that dated back form centuries. Most people agreed that Chaozhou culture is related to its minnan neighbor in Fujian province. Among the many Chazhou musical instrumental genres, Chaozhou xianshi is perhaps the most famous of all. It is a kind of amateur of minjian (folk) string ensemble popularized in the region since the 19th century and continues to be performed in informal settings such as community centers or neighborhood clubs and often for self-entertainment at present. Many music scholars view it as one of the major regional instrumental genres of China. Its social life relies on the patronage of mostly amateur musicians-this amateur ideal suggesting a strong influence of Confucian ideology and its elite origin. Usually there are two groups of participants - the musicians and the audience, the distinction being quite loosely defined. The musicians, who sit close to the center of the room, are those who would likely be asked to play. They take turns to perform and each play musician plays two to three pieces at a time. The audience consists mostly of friends, music lovers, and neighbors who enjoy listening this music and feel at ease socializing among themselves while the music is being played in the background (Lau 1994).

The instrumentation includes the characteristic Chaozhou two-string bowed lute erxian and other bowed and plucked strings such as the yehu, zhonghu, panghu, sanxian, pipa, zhongruan, and yangqin. With it unique high-pitched and thrilling timbre, the erxian is the leading instrument and the erxian player selects the pieces and sets the mode and tempo. The combination of timbres, as framed by the erxian, produces an unmistaken sound that has become butt of a Cantonese joke. As in other regional instrumental ensembles, each instrument of the xianshi elaborates on the main melody of the piece simultaneously thus creating a rich and compplicated heterophonic texture. The music follows a sequence of metric and tempo change decides on the spot by the musicians.

According to the traditional practice, the performance is often characterized by improvisation and flexibility. After the original form of the piece has been played once or twice, different variations of the piece will follow. The variation technique includes altering the density, melodic shape, rhythm, and tempo of the original music. This practice of flexibility is one that is scorned by many professional musicians. During my fieldwork in the area, I visited over 12 such clubs and some of them were active in the pre-revolutionary period. Having discussed the situation and reception of xianshi in China, I now move to the case study about Chaozhou xianshi in Thailand among Chinese migrants of Chaozhou descent in order to explore the meaning of this music in a different social context.

\section{Teochews (Chaozhouren) in Thailand}

It is common knowledge that Chinese have been in Thailand for centuries. Their presence in Thai society has been documented in both Chinese and Thai historical records as early as the 13th century. In the 16th and 17th centuries, Chinese from southern China began to migrate to Thailand in great numbers, taking advantage of the flourishing maritime trade as a means to search for a better living abroad (Amyot 1972, p. 76; Skinner 1957; Cushman 1993). Working mostly as traders, agricultural 
workers, and mediators between foreign merchants and local Thai, these early Chinese immigrants quickly established themselves as important players in the Thai economic infrastructure. Known as Teochews in Thailand and Southeast Asia Chaozhouren were by far the largest group (Skinner 1957, p. 179; 1958, p. 20; Purcell 1965). ${ }^{2}$ A powerful testament to the acceptance and visibility of the Chinese immigrant in Thai society, and consequently of the Teochew, is the fact that King Taksin (1767-1782), reportedly half Teochew, was able to become a Thai nobleman.

Migration of the Teochew to Thailand reached a new peak in the early part of the 20th century. According to Chinese customs statistics from 1918 to 1939, $55 \%$ of the Chinese immigrants arriving in Bangkok were from Swatow (Shantou), the provincial capital of Chaozhou in China (Skinner 1957, pp. 1979-1980). By the mid 20th century, an integral part of the Thai economy had been dominated by Thai businessmen of Teochew decent and this trend, continues into the present-day (Wu 1994; Hamilton \& Waters 1997). Therefore, it is not surprising that the Teochew have earned the reputation of being savvy entrepreneurs and diligent but stingy workaholics-a stereotype that still exists in contemporary Thai society (Tejapira 1997, p. 76). In fact many active contemporary Thai politicians and businessmen are of Chinese and Chaozhou heritage.

\section{Xianshi music clubs in Bangkok in the 1990s}

The existence of Chinese music is not new in Thailand. Murals of Chinese operatic scenes, dated back to the Ayutthaya period, suggest the long presence of Chinese performance in Thai culture (Wong 1998, p. 104). Although it is not known when Teochew music was first introduced in Thailand, many of my elderly Teochew informants were certain that amateur Teochew music clubs have existed in Thailand for over a century. The general impression, according to oral history told by their fathers and grandfathers, is that Teochew music clubs came into existence around the turn of century as the immigrants from Teochew were trying to reproduce a portion of home culture in their newly adopted country. It was also an effective way for them to create community in a foreign country. Around the mid-19th century the practice of amateur making music in music clubs began to gain popularity in the Teochew region of China among the literate upper classes particularly in urban areas. Performing the string xianshi ensemble music was a favorite pastime for the privileged class. Many music clubs were established in order to accommodate the growing demand for this kind of urban musical activity. Among the most notable ones in the capital city of Chazhou Shantou (the current socio-political center of the region) were Gongyishe, Yichengshe, Youshengshe, Nanxun Sizhushe (Xiao 1985, p. 94). Participating in these amateur musical activities not only fulfilled an aesthetic and pleasurable social function, it also tacitly marked a person's taste, regional affiliation, class, and social status because the amateur pursuit of arts and music was

\footnotetext{
${ }^{2}$ In hanyu pinyin, people from the Chaozhou region are known as Chaozhouren. But in most writings in Southeast Asian studies, they are known as Teochew, the phonetic equivalent of how the word Chaozhou is pronounced in Chaozhou dialect. I would use Teochew to refer to Chaozhouren in Thailand and other parts of Southeast Asia in this paper.
} 
a highly-revered virtue for the literati in the Confucian worldview (Levenson 1957; Xiao 1985). Because of the success and popularity of these few clubs, these early musical clubs have been considered by many Chaozhou musicians as models for other musical clubs both at home and in the diaspora. ${ }^{3}$ The early music clubs in Thailand were undoubtedly inspired by these organizations, and the resemblance between them is not difficult to a certain.

Given the inherent cultural and historical significance of amateur music making in the homeland, it is not surprising that music clubs in present-day Thailand strive to retain some of their original symbolic meaning even though their immediate environment has changed. I discovered a network of Teochew music clubs and musicians in Bangkok since the 1990s, and during my repeated visits, and at times long hours of observation, I began to realize the role these music clubs play in the construction and affirmation of identity for both the players and audiences. These clubs not only occupy an important facet of cultural life in the Teochew community, they also function as indispensable resources for Thai-Teochew who want to re-establish links to their ethnic roots. Nowadays, most clubs maintain a low public profile and are known primarily among members of the immediate social circle and neighborhood. They are self-contained groups that draw members by word of mouth and from introductions made by existing members. Unlike other formalized cultural organizations, they seldom publicize themselves, and many could be characterized as grassroots-type organizations such as those found in neighborhood or in private homes.

Although informal in structure, amateur musical clubs are similar in function and membership to most Chinese voluntary and clan associations in Thailand which are divided along ethnic, linguistic, familial lines. Each organization is considered an independent unit; however, players can and often do belong to more than one club. The written history of music clubs in Thailand has been spotty and incomplete because these clubs are usually invisible because they either have existed as informal groups or as ancillary organizations subsumed under larger clan associations. Available records show that one of the earliest formal Chinese music clubs is the Huaqiao Xinsheng Guoyueshe [Overseas Chinese New Sound National Music Association], a club that was established in Bangkok in 1925 (Chen 1975, p. 106). The name itself revealed the orientation and musical preference of this club. It was reported to be a music club devoted primarily to opera of the Hakka [Kejia] people, Hanju, and Hakka instrumental music, Handiao or hanyue (ibid).

Handiao or hanyue is known to Teochew musicians as weijiang music, literally music from the other side of the river because the Hakka region is located on the northeastern mountain of the Chaozhou region and the two regions are separated by a river. Because its origin can be traced back to an earlier vocal style qinqian, a elitist operatic style from central China during the late Ming dynasty, Teochew musicians in the early part of this century regarded it as more refined and elegant than the local Teochew musical genres (Xiao 1957, p. 86). Musicians in Thailand

\footnotetext{
3 Amateur Teochew clubs are a phenomenon found in many overseas Teochew communities such as those in Thailand, Singapore, Malaysia, Hong Kong, and Los Angeles. I have visited Teochew music clubs in many different locales and they are rather similar in their organization and operation. Almost all of them claimed to have been influenced by or remotely related to earlier music clubs in Chaozhou. Exchanges between the clubs and those in mainland happened quite frequently.
} 
also adopted this view and preferred it over Teochew music since the early 1920s. This explains why handiao had previously been popular among the Teochew speaking audiences in Bangkok and why it has been performed in music clubs there (Chen 1975, p. 106). Many older musicians I spoke to claim that most musicians of their fathers' generation could perform in both Teochew and Hakka styles but often prefer the latter when they were performing among Teochew friends. They further add that Handiao in Thailand began to decline after the 1950s because of the increasing demand for Teochew music and opera as a result of the growing prominence of the Teochew community.

The arrival of large numbers of new immigrants from Chaozhou in the early 20th century created a demographic shift and changed the power structure within the Bangkok Chinese community (Skinner 1957; Wu 1994; Zhang 1994). The Teochew community began to gain prominence and prestige. This shift is reflected in its extensive sponsorship of many diverse social and benevolent activities within the Chinese community. Performance of music and opera for religious ritual and for entertainment purposes often accompanied these frequently-held communal events. Teochew music and opera began to dominate other Chinese musical genres (Lai 1993, p. 195). Most of these ad-hoc music groups became attached to the clan associations, and very few managed to exist as independent organizations. Yearbooks of most Teochew clan associations invariably include a music group, with its membership and activities, as part of the regular function of the association.

The current socio-political attitude towards the Chinese has changed for the better in comparison to that of the previous times. During my research in 1994 and 1996, I located ten active independent music clubs in the city, each with 20 to 30 regular members, and I am aware that there are more clubs of various sizes scattered throughout the city. My lengthy interaction with the ten clubs I attended has provided me with a general view of how these clubs function and operate within the capital city. Despite the difference levels in financial support, the performance quality, repertory, attitude, and patterns of interaction in these clubs were comparable. The noticeable differences were in the décor of the clubs, the size of donations they receive, and the level of formality between the players. These variations seemed to be related to the economic status and level of education of the members. There also appeared to be a norm and expected behavior pattern in all the clubs. I have listed the names of the ten clubs in the following table in which I have given both their Chinese names and the pinyin romanizations. To the best of my knowledge, none of these music clubs has ever identified itself by a Thai name.

Music clubs are identified by an official name that is usually written on a plaque hung outside the club. Each name consists of two parts. The first is the proper name of the club. They vary in meaning; some are simple while others are more elaborate. For example, the club Daklakpu Guoyuezu took its name according to the district in the Thonburi area in which the club is located. The word "Daklapu" is the Chinese phonetic equivalent of the district name in Thai. ${ }^{4}$ The club Nanxun Sizhushe, is my

\footnotetext{
${ }^{4}$ Most Teochew-Thai I had encountered often referred to place Thai names in the city by their Chinese phonetic equivalent. It is clear that the usage of these names has been standardized in speech and in writing among the Teochew-speaking community in Bangkok.
} 
informant Ah Xing's favorite club. It adopted its name from a music club which existed in Chaozhou in the early 1920s. Perhaps the most revealing of all is the group that called itself with a poetic name Yeyun Ruyuexuan Quyituan-literally "leaf melody Confucian music room and art of singing group." The direct reference to the Confucian ideal in the club's endeavor is clear. The imagery of "melody" and "leaf" not only reflects the owner's literary background, but his poetic aspiration and overall understanding of Chinese elite culture. ${ }^{5}$

The second half of a club's name usually indicates the specific type or characteristics of the ensemble. These ranged from guoyuezu-national music group; guoyueshe-national music club; ruyueshe-Confucian music club; sizhushe-silk and bamboo music club; or quyituan-narrative and singing club. Even though the music performed in these clubs was rather similar, the labels reflect the different orientations and ideological distinctions of the individual club owner. It is rather telling that all ten clubs identified Teochew music either as Chinese music or national music rather than as regional music. Perhaps in their mind, xianshi music is their national music and being Teochew is the same as being Chinese. At a symbolic level, for these musicians Chineseness was linked first and foremost to being Teochew. Despite the different names, it is also clear that all music clubs were conscious of how they present themselves in public and their raison d'être. Here is the list of then clubs. It is interesting to note that some clubs preferred to use traditional Chinese characters to simplified one for their name. The name of each club also implies a unique history, purpose, origin of the founder, aesthetics, and mission.

\begin{tabular}{|c|c|c|}
\hline & Teochew music clubs & Chinese name \\
\hline 1. & Daklakpu Guoyuezu & 達叻蒲 國 樂組 \\
\hline 2. & Guangzheng Guoyushe & 光 正 國 樂 社 \\
\hline 3. & Guilin Chahuiyueshe & 桂林茶會樂社 \\
\hline 4. & Klong Tuey Lianyihui Guoyueshe & 孔堤聯誼會國 樂社 \\
\hline 5. & Luanxing Guoyueshe & 聯 興 國 樂社 \\
\hline 6. & Pusi Guoyueshe & 普師 國 樂社 \\
\hline 7. & Tongyue Yeyu Chaozhou Ruyueshe & 同 樂業 餘潮 州 儒 樂社 \\
\hline 8. & Xinxin Sizhushe & 欣 欣 絲 竹 社 \\
\hline 9. & Nanxun Sizhushe & 南薰絲竹社 \\
\hline 10. & Yeyun Ruyuexuan Quyituan & 葉 韻 儒 樂軒 曲㙯團 \\
\hline
\end{tabular}

The music clubs I visited were rather similar in size, organizational structure, activity, and in operation to each other and, as I was told, to those which existed earlier. Regardless of their size, organizational structure, funding, or location, the

\footnotetext{
5 The owner of this club Mr. Ong was born in Thailand in the early $1930 \mathrm{~s}$. After studying a few years at the local Chinese school, he was sent to Shantou of Teochew for schooling before the Second World War. $\mathrm{He}$ is proud of his knowledge of the Chinese classics and command of Mandarin Chinese. During my first visit, he spent a considerable amount of time making sure that I understand the literary reference in the name of his club.
} 
contemporary music clubs operated independently and each carried a distinct flavor based on the personality of its owner. For example, Pusi Guoyueshe was known to be critical musically while the practice sessions at the Yeyun Ruyuexuan Quyituan were often taped in order to offer players a chance to analyze their playing techniques. Nanxun Sizhushe was known as the most friendly club where all players regardless of musical ability were welcomed. Most clubs are supported by private donations, and, in many instances, the donors are mostly the members themselves and their friends who participate only as observers. Most places would put up a bulletin board listing monthly revenue and donors for members and the public. The funds are used to purchase instruments and pay necessary operating expenses such as rent, utilities, and supplies. I have also visited private music clubs that are sponsored entirely by individual well-to-do businessmen. Membership to these private clubs is generally closed and attendance usually requires an invitation or consent of the owner.

The clubs usually own collections of musical instruments that are used in typical Teochew music ensembles. These include the characteristic two-string bowed fiddle erxian-the leading instrument in a xianshi ensemble and an assortment of bowed and plucked strings such as the erhu, pipa, yangqin, sanxian. The type of music they perform is known as Chaozhou xianshiyue [Music for strings of Chaozhou] and Chaozhou opera, the two most popular genres in present-day Chaozhou in China.

In xianshi music, the two-string bowed fiddle erxian leads the music, and it is perhaps the most demanding instruments. Only respected musicians are invited to play this instrument. The erxian embellishes the main melody while the other bowed and plucked strings simultaneously perform a simplified version of the main melodic line. After the piece has been played once, a player proceeds into different variations. All musicians in the clubs I visited observed this practice during performance.

During the period of my observation, visitors to all of these clubs were mostly middle-aged, second or third generations Sino-Thai of Teochew heritage of both sexes (Lau 2001, 2004). The number of male members out-numbered female members. The division of labor appears to be a mirror image of the traditional Teochew social organization. Male members dominated the club business, and were usually in charge of setting up for each session and overall club maintenance. Women normally arrived a little later and mostly were not concerned with the business aspect of the club. Gender distinction was also reflected in the choice of music. Men performed exclusively Teochew instrumental music, and women usually sang excerpts from Teochew operas rather than playing instruments. In short, the meaning and identity of xianshi club and music varies according to the ethos and history of its practitioners and the specific socio-cultural context. What xianshi music means in Chaohou and within national music discourse has little bearing on how Thai-Teochew musicians view this music precisely because of the different processes of social imagination, identity formation, and power dynamics are at work in each locale. Now I turn to the case of jiangnan sizhu in Shanghai to offer more insights for discussion. 


\section{Jiangnan Sizhu in Shanghai}

Jiangnan sizhu is an instrumental ensemble music practiced primarily in the provinces of Jiangsu, Zhejiang, and Anhui of east central China. Developed in latenineteenth century by an emerging urban population for the purpose of selfcultivation and as music to accompany various social rituals (Witzleben 1995, p. 9; Gan 1985), this music began to take on distinct characteristics and gradually recognized as a musical emblem of the region generally known as jiangnan, south of the Yangzi River (Jones 1995, p. 270). While this music continued to be popular within this area, in recent years, however, it has become highly visible in other parts of the country and abroad, Largely due to the availability of various forms of media, publications and musical events of this kind of once little-known regional music. Despite the fact that it is a difang yinyue (regional music), it is not unusual and to hear it performed and to find printed music of jiangnan sizhu in cities such as Beijing, Guangzhou, Hong Kong, New York City, San Francisco and Singapore.

\section{Jiangnan sizhu and performance practice}

The standard instrumentation of a jiangnan sizhu ensemble consists of three groups of instruments. 1) Strings: erhu (the 2-string bowed fiddle), zhonghu (a medium-size bowed fiddle), sanxian (a long-neck plucked lute), pipa (a pear-shape plucked lute), qinqin (small plucked lute), and the hammer dulcimer-yanqin. 2) Winds: dizi (a traverse flute that leads the ensemble), xiao (a vertical flute), sheng (the mouth organ). 3) Percussion: bangu (a small flat drum), a pair of clappers, and occasionally pengling (a pair of small bells). The texture of this music is heterophonic, that is, each member of the ensemble simultaneously plays a variation of the same melody. The performance practice of fangman jiahua, literally means reducing the tempo and adding ornaments, is frequently used by local musicians to characterize this variation procedure. In western musical term, this simply means changing the texture by augmenting or elaborating the basic melody. This variation technique works at two levels.

At the macro level-fangman jiahua is the principle that produces variants of a tune. This process is found to be an important method that allows the tradition to create new identity and style from a preexisting composition. At the micro level- the principle of jiahua, usually improvised, allows musicians the freedom to add ornamentation, trills, short melodic embellishment to the melody while keeping the structure of the piece intact. A musician's competence and skills is often measured by his ability to improvise. This principle of variation is considered by many the essence in jiangnan sizhu performance.

In a traditional jiangnan sizhu ensemble, each player is expected to play a melodic line complimentary to the other voices and the ideal is to produce a smooth texture. One should be sensitive at all times and fills in the gap when necessary or backs off when the texture gets too dense. The dizi player usually leads the ensemble (highly embellished) and sets the tempo. The music is generally played in medium tempo and it progresses from slow to fast or from relax to intense. Although each player embellishes the melody according to the idiom of the 
instrument, certain stock melodic phrases would be favored by specific player thus rendering the rendition individualistic.

\section{Musical competency and meaning of Jiangnan Sizhu music}

The attitude towards jingnan sizhu is similar to that of Chaozhou xianshi. What is more telling concerning jiangnan sizhu tradition is the fact that my teachers, colleagues, and informants at the music conservatories and professional music institutions often view amateur musicians as unsophisticated and therefore their performance practice undesirable. In general, I often noticed that the musical ability of amateur musicians is surprisingly high and comparable to that of many professional musicians. This elitist attitude, mostly a result of the politicallyinformed musical ideals rather than based on actual musical competency, is pervasive among most professional musicians as they attempt to distinguish themselves, thereby reaffirming the superiority and authority of their musical ability, from those musicians who are not part of the official music establishment.

The approaches of jiangnan sizhu among the professional musicians are drastically different from those of the amateur. The instrumentation of the sizhu ensemble performed by the professional musicians is often unconventional, new instruments are often added depending on the performers' taste. In one performance, an orchestra consisting of traditional instruments was used in place of the three groups of instruments described above. In another case, only a dizi and an erhu are used in the ensemble. Modern performers of jiangnan sizhu strictly rely on the notation, while improvisation on the spot rarely occurs. New musical material and western harmonies are often added, as one of professional musicians claimed, "to enrich the texture of the existing melodies." 6 Dynamic contrast markings are provided in order to enhance the mood and accentuate various sections of the piece. These specific treatments of the music are in stark contrast to the traditional aesthetics which is to play as smooth as possible.

The attitude and disparaging comments towards regional genres such as jiangnan sizhu and xianshi only reaffirm the fact that, despite the deep meaning and symbolism of these genres to their practitioners, most conservatory musicians and state-sponsored music institutions still hold on to a fixed hierarchy of music that privileged new musical practice over traditional ones and a general disregard of the sentiments that have been generated through these music. This rigid and narrowly focused view runs against the grain of a flexible, fluid, reflexible, and dynamic notion of music identity that is at once context sensitive and local specific.

\section{Conclusion: music and local identity}

The case studies presented above describe two local music scenes and demonstrate that the identity of regional music cannot be easily collapsed into one singular

\footnotetext{
${ }^{6}$ Personal interview June 1992.
} 
definition using a rigid framework such as center and periphery or merely a general label called Chinese culture. Despite the similarities of performance practice, repertory, sonority, and aesthetics between the two musical genres, the meaning, symbolism, and ethos of these two musics are drastically different in different contexts and from one to the other. The ethnomusicologist Martin Stokes argues persuasively in his 1994 volume that all musical tradition possesses both a spatial and temporal dimension and its existence hinges on unique balance of the two. Any performance, he argues, inevitably conjures up collective memories of place and ethnicity, enabling practitioners to connect themselves to a specific locale and to create a sense of belonging. Thus, when Chaozhou musicians dismissed Hakka musicians' performance of their repertory as lacking in flavor (weidao), the criticism was based not so much on their playing techniques, but rather on the grounds that they were not connected to the place called Chaozhou and that they are Chaozhouren. In other words, place of origin, native ways of thinking about place, and ethnicity all plays a vital role in shaping local definitions, practice, and perceptions of music. But these deep-seated sentiments are often unspoken, understood, and often expressed in the name of other concerns. The same music was viewed by zhuanye professional musicians as backward and unsophisticated in one context when performed in the diaspora was able to conjure "deep" Teochew sensibilities and national sentiments meaningful only to musicians of Chinese descent within the diasporic space.

Amongst various approaches to discussing Chinese ethnicity and identity, the concept of native birthplace (jiguan) has been recognized as an important frame of reference in inter-personal communications and inter-group relationships (Honig 1992; Rowe 1989; Naquin \& Rawski 1987). It has consistently provided a powerful point of contact for connecting members of specific ethnic groups in various circumstances (Honig 1992, p. 6). In her study of Subei people in the north part of Shanghai city, Emily Honig remarks "ethnicity involves the creation, invocation, and manipulation of cultural distinctiveness to establish self/other dichotomies among people in a shared political and economic system" (ibid: 9). Local musicians I have interviewed in various places frequently associated one's place of origin with authentic musical practice. In short, authenticity in performance for them is "constructed based on a sense of" essential(ized self, a collective claimed identity, and not a learned behavior (Stokes 1994). Earlier, I suggested that identity is fluid and exists in multiple layers depending on context. A study of local musics without exploring the contexts and processes in which they were created, defined, and redefined renders them meaningless and unimportant from insiders' or outsiders' perspectives. Contexts are the defining condition in the production of meaning and sociality within culture. From this observation, several important questions emerged: What are the different forces that motivated each instance of the identity? Who owns the script and for whom is the story told?

The views that local music is inferior on the one hand, and an emblem for local consciousness on the other are equally valid and not mutually contradictory. They clearly have nothing to do with the inherent quality, timbre, performance practice, aesthetics of the music; rather, it concerns the politics of music, and in our studies, the particularities of post-1949 culture, ethnic relationships in contemporary China, 
and the dynamics among the different groups of musicians in each locales. By focusing on the contexts in which criticism was launched, dynamics between musical preferences, and the social positions of those who are defining and who can speak, we can then begin to understand the complexity surrounding the questions of identity formation and processes of identification.

The notion that local music is backward and object of exoticism has been constructed in the process of establishing a national musical culture. It is a byproduct in legitimizing the raison d'etre of the new national musical practice and authority. During this process, the state-sponsored professional zhuanye musicians have distanced themselves from the local musical practices and branded them as the exotic "others." At the same time, these professional musicians are able to assert their superiority and dominance over the local amateur musicians in the cultural and political hierarchy because of their elevated social status (Bourdieu 1984). Playing in teahouses for zhuanye musicians is considered crude, improper, and amateurish because these amateur activities lack prestige, specificity and uniformity-central and crucial elements of the institutionalized national musical practice. Local musicians, however, view this differently because their community of sentiments is based on different assumptions, values, and criteria.

To practitioners of xianshi music in Chaozhou and jiangnan sizhu in Shanghai teahouses, their music is never unsophisticated and unscientific but it is real and meaningful because the same consciousness that informs their local identity and consciousness also guides their performance and gives meaning to their practice. This consciousness or cultural conditioning, realized by the collective imagination through a community of shared sentiment, history, and experience, is always taken for granted, thus goes without saying because it is unconditional, uncontested, and accepted as natural by members of a particular group (Becker 1981; Turino 1989). It is therefore not surprising that the local Chaozhou players view their music in terms of regional affiliation and sensibilities because they find them natural and "unchallenged." However, when this identity is questioned, challenged or threatened, it becomes latent and gives way to the dominant discourse, such as that proposed by the professional musicians. However, deep down they always maintain the values and continuity of their music. As a case in point, during the 1950s in Thailand when the anti-Chinese sentiments were at its peak, Chinese were required by law to curtail signs that would emphasize Chineseness. This included all kind of ethnic Chinese activities, events, and even using Chinese names. Even in the face of this hash reality, my informants told me that musicians never stopped playing their music despite the fear of retaliation. The only thing they did differently is that they would only play privately. As to why they would continue to play in such adverse situations, informants invariably answered that music offered an indispensable sense of belonging and identity as Teochew and as an antidote to the oppressive Thai political policy. Music strengthened their resolve to adhere to their own identity. To them, their identity through their music never quite vanishes; it retains currency as the context allows, as when Teochew music is performed openly in parks every weekend in Central Bangkok. Along similar lines, while most local musicians readily admitted that they feel local music is backward and crude, they have no intention of changing it or abandoning it. In fact new music clubs are continually 
being formed in both Chaozhou and Shanghai in recent years, and xianshi and jiangnan sizhu music continues to contribute to a sense of identity through the direct experience it provides for its practitioners vis-à-vis its social meanings. As a flexible and highly malleable non-verbal art form that is capable of crossing boundaries, music is a vehicle that takes performers and listeners to a place beyond prescribed spatial limits, a place where they need to be.

\section{References}

Amyot, J. (1972). The Chinese and the national integration in southeast Asia. Bangkok: Institute of Asian Stuides, Chulalongkorn University.

Appadurai, A. (1996). Disjuncture and difference in the global cultural economy. In A. Appadurai (Ed.), Modernity at large: Cultural dimensions of globalization (pp. 27-47). Minnesota: University of Minnesota Press.

Becker, J., \& Becker, A. (1981). A musical icon: Power and meaning in Javanese gamelan music. In W. Steiner (Ed.), The sign in music and literature (pp. 203-215). Austin: University of Texas Press.

Bourdieu, P. (1977). Outline of a theory of practice. Cambridge, MA: Harvard University Press.

Bourdieu, P. (1984). Distinction: A social critique of the judgement of taste. Cambridge, MA: Harvard University Press.

Chen, Z. (1975). Taihuaqiao Tuanshilu (A brief history of Overseas Chinese Association in Thailand). Bangkok: Sihai Chubanshe (Four Seas Publishing Company).

Chow, R. (1998). On Chineseness as a theoretical problem. Boundary 2, 25(3), 1-24.

Clifford, J. (1988). The Predicament of Culture. Cambridge, MA: Harvard University Press.

Cushman, J. W. (1993). Fields from the Sea: Chinese Junk Trade with Siam During the Late Eighteenth and Early Nineteenth Centuries. Ithaca: Southeast Asia Program, Cornell University.

Ding, S. (1964). Dui Yinyue Chuangzuo minzuhua wenti de tansuo [On the Issue of Creating a Nationalized Music]. Beijing: Wenhuibao [The Art Alliance Newspaper].

Frith, S. (1996). Music and identity. In P. Du Gay \& S. Hall (Eds.), Questions of cultural identity (pp. 108-127). London; Thousand Oaks, CA: Sage.

Gan, T. (1985). Jiangnan sizhu Yinyue [Jiangnan sizhu Music]. Nanjing: Jiangsu Remin Chubanshe [Jiangsu People's publishing Company].

Hamilton, G., \& Waters, T. (1997). Ethnicity and Capitalist Development: The changing Role of the Chinese in Thailand. In D. Chirot \& A. Reid (Eds.), Essential outsiders: Chinese and Jews in the modern transformation of Southeast Asia and Central Europe (pp. 258-284). Seattle: University of Washington Press.

Ho, V. (2005). Understanding canton rethinking popular culture in the republican period. Oxford and London: Oxford University Press.

Honig, E. (1992). Creating chinese ethnicity: Subei people in Shanghai, 1850-1980. New Haven: Yale University Press.

Jones, S. (1995). Folk music of China: Living instrumental traditions. New York and Oxford: Oxford University Press.

Kopytoff, I. (1986). The cultural biography of things: Commoditization as process. In A. Appadurai (Ed.), The social life of things: Commodities in cultural perspective (pp. 64-91). Cambridge: Cambridge University Press.

Lai, B. J. (1993). Dongnanya huawen xiqu gaiguan [A survey of Chinese opera opera in Southeast Asia]. Beijing: Zhongguo xiqu chubanshe [Chinese Operaand Drama Publishing Company].

Lau, F. (1994). Chaozhou Music in the 1990s: The Survival of a Regional Music. In L. Tay (Ed.), Chaozhouxue Guoji Yintaohui Lunwenji [Collected Essays of the Conference on Chaozhou Studies] (Vol. 2, pp. 440-455). Guangzhou: Jinan University Press.

Lau, F. (2001). Performing identity: Musical expression of Thai-Chinese in contemporary Bangkok. SOJOURN, 16(1), 38-70.

Lau, F. (2004). Morphing Chineseness: The changing images of amateur Chinese Music Clubs in Singapore. In U. Hae-kyung (Ed.), Diasporas and interculturalism in Asian performing arts: Translating traditions (pp. 30-42). London: Curzon Press. 
Lau, F. (2008). Nationalizing sound in the age of modernity. In W.-K. Chow, T.-K. Hon, \& H.-Y. Ip (Eds.), Beyond the May fourth paradigm: In search of Chinese modernity (pp. 209-228). Lanham, MD: Lexington Books/Rowman \& Littlefied.

Lee, L. O.-F. (1999). Shanghai modern: The flowering of a new urban culture in China 1930-1945. Cambridge, MA: Harvard University Press.

Levenson, J. (1957). The amateur ideal in Ming and early Ch'ing society: Evidence from painting. In J. Fairbank (Ed.), Chinese thought and institutions (pp. 320-341). Chicago: University of Chicago Press.

Mercer, K. (1992). ‘1989’: Periodizing Politics and Identity. In L. Grossberg, C. Nelson, \& P. Treichler (Eds.), Cultural Studies (pp. 420-438). London: Routledge, Chapman and Hall, Inc.

Naquin, S., \& Rawski, E. (1987). Chinese Society in the Eighteenth Century. New Haven: Yale University Press.

Purcell, V. (1965). The Chinese in Southeast Asia (2nd ed.). Kuala Lumpur: Oxford University Press.

Robbins, J. (1989). Practical and abstract taxonomy in Cuban Music. Ethnomusicology, 33(3), 379-390.

Rowe, W. (1989). Hankow: Conflict and community in a Chinese City, 1796-1895. Stanford: Stanford University Press.

Siu, H. (Ed.). (2010). Merchants' daughter: Daughters, women, commerce and regional culture in South China. Hon Kong: Hong Kong University Press.

Skinner, G. W. (1957). Chinese society in Thailand: An analytical history. Ithaca: Cornell University Press.

Skinner, G. W. (1958). Leadership and power in the Chinese community of Thailand. Ithaca: Cornell University Press.

Stokes, M. (1994). Place, exchange, and meaning: Black Sea musicians in the west of Ireland. In M. Stokes (Ed.), Ethnicity, identity and music: The musical construction of place (pp. 97-116). Oxford, Providence: Berg Publishers.

Tejapira, K. (1997). Imagined uncommunity: The lookjin middle class and Thai official nationalism. In D. Chirot \& A. Reid (Eds.), Essential outsiders: Chinese and Jews in the modern transformation of southeast Asia and Central Europe (pp. 75-98). Seattle and London: University of Washington Press.

Turino, T. (1989). The coherence of social style and musical creation among the aymara in Southern Peru. Ethnomusicology, 33(1), 1-30.

Turino, T. (1991). The history of a Peruvian Panpipe Style and the politics of interpretation. In S. Blum, P. Bohlman, \& D. Newman (Eds.), Ethnomusicology and modern music history (pp. 121-138). Urbana: University of Illinois Press.

Waterman, C. (1990). 'Our tradition is a very modern tradition': Popular music and the construction of Pan-Yoruba identity. Ethnomusicology, 34(3), 367-379.

Witzleben, L. (1995). "Silk and bamboo" Music in Shanghai: The Jiangnan Sizhu instrumental ensemble tradition. Kent, $\mathrm{OH}$ and London: The Kent State University Press.

Wong, I. (1985). The many roles of peking opera in San Francisco in 1980s. UCLA Selected Reports in Ethnomusicology, 6, 173-188.

Wong, D. (1998). Mon music for Thai deaths: Ethnicity and status in Thai urban funerals. Asian Folklore Studies, 57, 99-130.

Wu, F. (1994). Chaoren zai Taiguo de fazheng yu gongxian [The Contribution and Development of Teochew in Thailand]. In L. Tay (Ed.), Chaozhouxue Guoji Yintaohui Lunwenji [Collected Essays of the Conference on Chaozhou Studies] (Vol. 2, pp. 1001-1024). Guangzhou: Jinan University Press.

Xiao, Y. (1985). Chaozhou Xiqu yinyuezhi [A study of Chaozhou music and opera]. Penang: Guangyin chubanshe [Guangyin Publishing Company].

Yang, M. (1994). Academic ignorance or political taboo? Some issues in China's study of its Folk Song Culture. Ethnomusicology, 38(2), 303-320.

Zhang, Y. (1994). Jindai Menggu huaren shequ de Chaoshan wenhua tezheng chutan [A preliminary study of the Chaozhou cultural traits among the Chinese in contemporary Bangkok]. In L. Tay (Ed.), Chaozhouxue Guoji Yintaohui Lunwenji [Collected essays of the conference on Chaozhou studies] (Vol. 2, pp. 947-965). Guangzhou: Jinan University Press. 